AVALIAÇÃO SÓCIO-AMBIENTAL EM COMUNIDADES RECEPTORAS: UMA CONTRIBUIÇÃO AO ESTUDO DOS IMPACTOS DA ATIVIDADE TURÍSTICA NA VISÃO DOS MORADORES DA VILA DE PONTA NEGRA, NATAL/RN

\author{
Aline Gisele Azevedo Lima \\ Programa de Engenharia da Produção - CT/UFRN \\ aline_pep@yahoo.com.br \\ Sérgio Marques Júnior \\ Professor do Departamento de Agropecuária - CT/UFRN \\ sergio@ct.ufrn.br
}

\title{
RESUMO
}

O presente trabalho teve como objetivo investigar os impactos sócio-ambientais advindos da atividade turística a partir da visão de uma comunidade receptora. Para tanto, foram enfocados aspectos ambientais, sociais, econômicos, além de apresentar o desenvolvimento sustentável no turismo, conceitos de indicadores e modelos de métodos de avaliação sócioambiental como forma de incrementar a avaliação proposta neste estudo. Foi realizada uma pesquisa amostral do tipo Survey com 100 habitantes da Vila de Ponta Negra, uma comunidade inserida em uma das principais regiões da atividade turística da cidade do Natal, capital do Estado do Rio Grande do Norte, e que consequentemente vem sofrendo com os impactos do crescimento desta atividade. O instrumento de pesquisa utilizado foi o formulário, estruturado com perguntas abertas e fechadas. O método de coleta de dados foi a entrevista pessoal. Os resultados mostram que a população estudada percebe que a educação, o emprego, a distribuição de renda e o lazer, possuem uma relação direta com os benefícios sociais advindos do turismo. Entretanto, não percebem uma relação no que se refere à saúde e a qualidade de vida. Já aspectos como impactos ao meio ambiente, prostituição, criminalidade e violência, são percebidos, na visão da comunidade, como problemas, mas que não influenciam diretamente na geração de benefícios sociais para a comunidade.

PALAVRAS-CHAVE: Turismo, Impactos sócio-ambientais, Avaliação. 


\section{AVALIAÇÃO SÓCIO-AMBIENTAL EM COMUNIDADES RECEPTORAS: UMA CONTRIBUIÇÃO AO ESTUDO DOS IMPACTOS DA ATIVIDADE TURÍSTICA NA VISÃO DOS MORADORES DA VILA DE PONTA NEGRA, NATAL/RN}

\section{INTRODUÇÃO}

O turismo é considerado uma das maiores atividades econômicas da atualidade com um faturamento mundial estimado em US\$ 681,5 bilhões, sendo no Brasil em torno de 4,3 bilhões, que em 2006 empregava um trabalhador em doze, em termos mundiais (BRASIL, 2006). Trata-se de um fenômeno que deveria preocupar-se com o desenvolvimento sustentado, porque depende intrinsecamente dos recursos da natureza e da herança cultural da sociedade. O turismo vende esses recursos como parte de seu produto empírico, mas também precisa compartilhar dos mesmos recursos com outros usuários, inclusive a população local, que muitas vezes tem no turismo a principal fonte para o seu desenvolvimento. Conseqüentemente, é do próprio interesse do turismo buscar ativamente o desenvolvimento sustentado e cooperar com outros grupos, setores e governos para garantir a integridade de seus recursos.

Mas o que se tem observado é um crescimento desordenado gerador de impactos, positivos e negativos, sendo esses últimos, quase sempre, em maior proporção, principalmente em relação ao meio ambiente e a população local, esquecendo-se que estão na natureza e nas características específicas da localidade os atrativos essenciais dessa atividade.

Para que se possa entender o atual estágio da atividade turística é necessário fazer uma retrospectiva histórica no que diz respeito ao processo de urbanização, ao sistema industrial e pós-industrial da sociedade contemporânea, pois esses acontecimentos implicaram no aparecimento e desenvolvimento do lazer, como necessidade a ser satisfeita, e consequentemente do turismo.

Atualmente, com a globalização essa busca desenfreada pelo preenchimento do tempo livre com o lazer se torna mais visível. O lazer, como necessidade numa sociedade que precisa estar em equilíbrio e gerar novas fontes econômicas, ganha um ritmo acelerado. O turismo é uma dessas formas de lazer, procurando organizar e planejar o tempo livre da sociedade atual. Ele passa a exigir novos modelos de espaços que correspondem aos novos tipos de relações no nível humano, além de contribuir para a circulação de capital, melhoria econômica de uma região e o consumo dos lugares e do meio ambiente.

O turismo, segundo Bissoli (1992), é entendido como o conjunto de recursos capazes de satisfazer as aspirações mais diversas, que incitam o indivíduo a deslocar-se do seu universo cotidiano, e assim caracterizar-se por ser uma atividade essencialmente ligada à utilização do tempo livre.

Assim, a atividade turística surge como resposta a uma necessidade de descompressão, resultante da própria dinâmica do sistema da sociedade industrial e pós-industrial e do processo de urbanização, que ao mesmo tempo em que cria e aumenta o tempo livre e a necessidade do lazer não consegue atender à população, deixando para o turismo o papel de cumprir tal designação. 
Para entender a atividade turística se faz necessário reforçar a importância do meio ambiente, pois grande parte dessa atividade tem como base a organização, o planejamento e o consumo desse meio, onde as experiências concebidas pelo turismo se desenrolam.

O termo meio ambiente provém do latim medium (meio), que se refere ao lugar onde qualquer ser vivo pode ser encontrado e ambire (ambiente), que se relaciona a tudo que envolve esse lugar. Portanto, o ambiente reforça o conceito de meio, repassando a idéia de entorno ou da realidade física que envolve todos os seres vivos.

Santos et al (1994), verifica que o meio ambiente é o que se pode chamar de Sistemas da Natureza sucessivos, que inclui os objetivos, as ações, as crenças, os desejos, a realidade esmagadora e as perspectivas, onde esta é continente e conteúdo do Homem. E ainda, segundo Ferreti (2002), o termo meio ambiente envolve o ser humano e toda sua evolução, inclusive a tecnológica.

A confluência entre esses dois setores de grande interesse na atualidade, o turismo e o meio ambiente, contempla vários enfoques, o que incentiva o estudo das inter-relações e, principalmente, do entendimento das influências que se estabelecem entre esses setores.

Atualmente, a globalização tende a tornar a natureza mundial, tornando-a tecnificada/hostil, dominada por certos grupos sociais que imprimem uma nova relação, não mais de complementaridade, mas sim de exploração. A atividade turística está presa ao processo de mundialização, portanto utilizando-se dessa natureza/ambiente hostil.

É pela utilização desse falso ambiente que o turismo caminha. Esse processo acaba por transmitir uma realidade falsa e comprometedora para a atividade turística que deveria ter por base o espaço local, real.

A globalização, dessa forma, tende a tornar os espaços iguais. Ou seja, uma homogeneização fragmentária, dominada pelos grandes capitais e movida constantemente pela competição mundial.

A natureza se vê equiparada a qualquer outra mercadoria. O consumidor é induzido a comprar a paisagem, como bem de consumo no supermercado. O processo de convencimento, que é ideológico, é o mesmo. Produz-se, recorta-se, escolhe-se o que se vai mostrar, vende-se e ainda se garante a satisfação. A paisagem não é construída em cima do vazio. Ela é feita a partir de interesses, levando-se em conta tendências do mercado. Há uma turistificação não só da natureza, mas da própria sociedade. O turista entra na contabilidade do negócio e sua subjetividade é trabalhada por uma objetividade que determina os lugares aonde ele deve ir.

O processo de globalização exige uma velocidade de transformação dos lugares que afeta diretamente o ambiente. Esses lugares produzidos e comercializados constituem matériaprima para o turismo. Este, muitas vezes, afirma o processo de globalização dos lugares, sem refletir essa ação que necessita da singularidade do ambiente para efetivar plenamente suas atividades.

Ao verificar o fenômeno do turismo sob as perspectivas da globalização observa-se que essas atuais premissas impostas pela nova ordem mundial, de construção de novos lugares, vão de encontro aos objetivos desta atividade. Começando pelos próprios consumidores do 
turismo: os turistas. Destes, desejos e necessidades não são satisfeitos, pois um indivíduo em viagem, principalmente de lazer, busca ao se deslocar de suas cidades de origem a outras localidades, o desejo de evasão, de fuga da rotina, a busca por novas paisagens, novos estilos de vida, que muitas vezes não são atingidos simplesmente pelo fato dos lugares serem praticamente iguais. Não ocorre, assim, a mudança de vida, mesmo que por um determinado período, tão desejada. Segundo Urry (1996), o turista, sai de seu domicílio para procurar o diferente, o inusitado, e não espaços já vistos, (re)criados e globalizados.

Considerando o turista um elo muito importante para o turismo, não se pode esquecer que não existe turismo sem meio ambiente e população local, sem a cidade a receber. Por isso que a presente pesquisa enfoca esses dois setores, pouco estudados e sem a devida importância que realmente possuem. Sendo assim, é preciso considerar o estudo das interrelações e, principalmente, do entendimento das influências que se estabelecem entre o meio ambiente e a população local, para que realmente possa-se ter um turismo ordenado que produza benefícios não só para quem visita, ao ver paisagens, mudar de vida, mas também, e principalmente, aos dois elos menos favorecidos com a expansão da atividade turística: o meio ambiente e a comunidade.

O turismo ao se estabelecer em uma localidade, na maioria das vezes, surge à primeira vista, como uma "tábua de salvação" para problemas da comunidade, devido ser um gerador de emprego e distribuidor de rendas. Mas, a longo prazo, devido a falta de um planejamento prévio, as mudanças na localidade que deveriam ser símbolo de desenvolvimento começam a aparecer como mazelas que assolam toda uma estrutura social.

Assim, a não consideração do nível de desenvolvimento da comunidade, o tipo de turismo a que a comunidade fica exposta e a falta de um planejamento, resultam no atual estágio em que muitas comunidades receptoras se encontram: tentando solucionar os impactos negativos, ressaltando-se alto índice de prostituição, marginalidade, uso de drogas, poluição, descaracterização das paisagens, especulação imobiliária, falta de infra-estrutura adequada, deslocamento dos antigos moradores para áreas afastadas, entre outros. Assim, uma atividade que inicialmente seria a salvação para os problemas de uma sociedade, aparece como o principal agravante desses impactos negativos.

Embora esse setor seja considerado menos agressivo para o ambiente que a maioria das atividades econômicas, como relata Ouriques (2005), suas dimensões e sua presença difusa em algumas locações, como se pôde observar, têm conseqüências negativas para o meio ambiente, em termos físicos e sociais. Desta forma, requere-se uma administração mais ampla dessa atividade, para estimular uma maior participação do governo e um número maior de parcerias entre setores público e privado. Ou seja, prevalecer a necessidade de se desenvolver formas alternativas de turismo com uma abordagem mais sistêmica, visando a beneficiar os visitantes e principalmente os visitados.

Como alternativa, pode-se discutir o turismo como uma atividade sustentável, baseando-se nas premissas da sustentabilidade que evoca a importância de harmonizar as necessidades de seus quatro componentes: a comunidade receptora, os visitantes, o meio-ambiente e a própria atividade. Também, com a finalidade de se ampliar os conhecimentos, a utilização de indicadores como instrumentos auxiliar, na compreensão de fatos sócio-ambientais, se revela como uma ferramenta rica de informações. Principalmente, quando se busca 
verificar qualquer situação em que a população local seja o ator fundamental para uma avaliação.

Assim, é nessa perspectiva que a presente pesquisa pretende desenvolver um estudo no qual se considere os impactos sócio-ambientais sobre uma comunidade receptora como um fator primordial de análise da atividade turística na localidade, para posteriormente se desenvolver um turismo que venha valorizar os recursos sociológicos, direcionar equipamentos e infra-estrutura, considerando anseios, crenças e valores da população tradicional, pois está nesses elementos um dos principais atrativos para um indivíduo sair de sua residência a procura do inusitado, de um lugar onde possa "renovar suas energias". É nesse sentido que aparece, com a ajuda de indicadores, a premissa do turismo sustentável, que busca justamente na população local as bases para seu desenvolvimento.

É diante desse contexto, que se questiona como as populações locais percebem os impactos sócio-ambientais, positivos e negativos, advindos da atividade turística, em suas comunidades.

\section{OBJETIVO}

Investigar os impactos sócio-ambientais advindos da atividade turística a partir da visão de uma comunidade receptora.

\section{RELEVÂNCIA}

A atividade turística é conhecida pela sua capacidade econômica de geração de emprego e renda. Apresenta-se como uma das maiores atividades econômicas da atualidade, gerando divisas na casa dos bilhões mundialmente. Gera lucros, tanto para os "produtores", como para a região à qual está inserida, não só pela geração de empregos, como também pela geração de dividendos, uma vez que movimenta a economia melhorando o desempenho da balança comercial, não só da localidade e do estado, como do próprio país. No entanto, pouco se tem pesquisado a respeito dos impactos positivos e negativos, sociais e ambientais para a população local como um todo. O que se observa são estudos concentrados na medição de impactos e benefícios mais tangíveis, como os econômicos. Valorizando-se excessivamente os impactos positivos, deixando de lado as conseqüências indesejáveis, restringindo a amplitude e a exatidão dos estudos voltando-se para as análises de situações específicas de forma isolada.

É com a pretensão de melhor compreender os impactos causados pelo crescimento do turismo em uma determinada comunidade, que, neste estudo, considerou-se alguns indicadores sócio-ambientais, representando recortes da realidade vivenciada, por ser instrumentos que auxiliam na representação dessa realidade, possibilitando a construção do panorama das condições dos espaços observados no qual uma avaliação deve se basear. "Considerando que o turismo é uma atividade dinâmica e que os impactos e suas conseqüências mudam constantemente - como conseqüência das modificações dos objetivos, tanto dos turistas como das comunidades receptoras das flutuações nos processos relacionados com a economia, o meio ambiente e com as mudanças tecnológicas - o seu monitoramento periódico torna-se uma necessidade imprescindível.” (RUSCHMANN, 2001, p.36) 
Nesse sentindo, entende-se a relevância da presente pesquisa em contribuir na apresentação de algumas situações inerentes à atividade, quanto aos impactos positivos criados pelo setor, e principalmente pelos impactos negativos sociais e ambientais, trazendo subsídios às autoridades, aos órgãos interessados e a população local em geral para a tomada de decisão, quanto ao apoio e melhor compreensão desse segmento.

Do ponto de vista acadêmico, visa-se contribuir com a geração de informações e dados que auxiliem os estudos de avaliação sócio-ambiental, assim como na identificação de fatores direcionadores de uma comunidade receptora frente à atividade turística, contribuindo na construção do conhecimento para tomadas de decisão mais apropriadas à realidade do setor.

\section{METODOLOGIA DA PESQUISA}

\subsection{População em Estudo}

Como população a ser estudada, a presente pesquisa selecionou os habitantes da Vila de Ponta Negra, uma comunidade da cidade do Natal, capital do Estado do Rio Grande do Norte. Essa população foi baseada em um percentual estatístico constante no Censo Demográfico de 2000, do Instituto Brasileiro de Geografia e Estatística - IBGE (2003), considerando-se um morador por domicílio, catalogando-se na Vila de Ponta Negra, 2.387 (dois mil trezentos e oitenta e sete) domicílios particulares.

\subsection{Plano Amostral}

O presente trabalho caracteriza-se por ser uma pesquisa não-probabilística acidental, considerando o total de domicílios particulares da Vila de Ponta Negra como população, sendo sua amostra determinada pelo modelo de Triola (2005) de acordo com a equação:

$$
n=\frac{N \hat{p} \hat{q} Z^{2}}{\hat{p} \hat{q} Z^{2}+(N-1) \varepsilon^{2}}
$$

\subsection{Instrumento de Coleta de Dados}

Utilizou-se um formulário estruturado com perguntas abertas e fechadas, as quais podem contribuir para mensurar e avaliar os parâmetros antecedentes e conseqüentes da avaliação sócio-ambiental da atividade turística na Vila de Ponta Negra, sob ponto de vista dos moradores. 
As variáveis mensuráveis foram selecionadas de acordo com os indicadores sociais que o IBGE utiliza em seus estudos, como aspectos demográficos, trabalho e rendimento, educação e condições de vida (IBGE, 1997)

\subsection{Método de Coleta de Dados}

O presente estudo caracteriza-se por ser uma pesquisa exploratória descritiva do tipo survey, com utilização de um formulário estruturado, como instrumento de pesquisa, e a entrevista pessoal como método utilizado para a coleta de dados.

\subsection{Técnicas de Análise dos Dados}

Os dados foram analisados de duas formas: técnicas descritivas e exploratórias, a partir de uma estatística descritiva; e através da análise de regressão múltipla, que possibilita entender que a variável dependente está sendo explicada, enquanto que as variáveis independentes estão fazendo a predição da variável dependente.

Forma geral da equação de regressão múltipla estimada:

$$
y=b_{0}+b_{1} x_{1}+b_{2} x_{2}+\ldots+b_{k} x_{k}+\varepsilon
$$

\section{CONCLUSÃO}

A primeira conclusão que pode-se chegar sobre a atividade turística em relação aos impactos sócio-ambientais analisados sob a ótica de uma população receptora é a geração de emprego e renda, talvez por serem os benefícios mais perceptíveis ou mesmo por serem os mais divulgados e fáceis de quantificar. Principalmente, quando se trata da análise do poder público, quando se diz que o turismo é a maneira mais rápida de se mudar os indicadores sociais das pessoas, sendo uma área que movimenta muitos recursos e que oferece mais possibilidades de emprego. (FARIA, 2007).

Neste trabalho, pode-se comprovar que esse pensamento é o que ainda prevalece. Principalmente, através da análise descritiva, na qual as variáveis são analisadas uma a uma, verifica-se que as únicas variáveis que sofreram alguma melhora foram justamente o emprego e a renda. Já os benefícios sociais e a qualidade de vida permaneceram do mesmo jeito, sendo perceptível uma melhora sutil e a distribuição de renda tendendo para uma pequena baixa.

Variáveis como saúde, educação e lazer, obtiveram respostas negativas em seu crescimento. Essa situação pode ser comprovada, pelo baixo nível de escolaridade da população estudada a qual 57\% possui apenas o nível médio, 21 \% o ensino fundamental e $22 \%$ o ensino superior.

Já variáveis como, criminalidade, violência e prostituição obtiveram respostas muito negativas. Essa realidade é comprovada quando autores como Ruschmann (2001) e Archer e Cooper (2002), explicam que a não consideração do nível de desenvolvimento da comunidade, o tipo de turismo que é desenvolvido e a falta de um planejamento, têm como resultado a tentativa de se solucionar os impactos negativos, como o alto índice de 
prostituição, marginalidade, uso de drogas, poluição, descaracterização das paisagens, especulação imobiliária, falta de infra-estrutura adequada, entre outros.

Outra variável bastante negativa foi o impacto ao meio ambiente. Como foi uma questão abrangente, teve-se que explicar o que significa "impacto ao meio ambiente" às pessoas entrevistadas. Mesmo com alguma dificuldade para entender o termo o percentual do impacto ao meio ambiente aumentou bastante. Infelizmente, essa é uma realidade frustrante para o turismo e para a sociedade, além de ser o meio ambiente onde tudo se desenrola, seja para o turismo ou não, é nele que está a matéria-prima desta atividade, como a paisagem, a cultura da população local. Enfim, se é preciso desenvolver e construir estrutura para a atividade turística que se faça com planejamento e responsabilidade, pois por suas próprias características há uma apropriação direta ou indireta e uma produção espacial simbólica da beleza natural ou da cultural, alterando-se tanto a paisagem física como as relações sociais dos moradores da área que passam a gravitar em torno da atividade turística.

Assim, se conclui, com a análise descritiva, que no impacto do turismo, os positivos, são os empregos e renda gerados, surtindo efeito na distribuição de renda. Os impactos negativos refletem o que muitos autores pesquisados abordam: o aumento da criminalidade, da violência, da prostituição, da degradação ao meio ambiente, do uso de drogas, agravados, também, pela péssima condição da educação, da saúde e dos espaços de lazer. Constatados nos depoimentos dos moradores da Vila de Ponta Negra entrevistados.

Com relação à análise de regressão múltipla, foi identificada como variável dependente a BEN_SOCI (Opinião do entrevistado quanto os benefícios sociais na comunidade gerados pela atividade turística) e como variáveis independentes que se relacionaram à dependente, EMPREGO (Opinião do entrevistado quanto à situação do emprego na comunidade devido à atividade turística.), EDUCAÇÃO (Opinião do entrevistado quanto à situação da educação devido à atividade turística), DIST_REN (Opinião do entrevistado quanto à situação da distribuição de renda na comunidade devido à atividade turística), SAUDE (Opinião do entrevistado quanto à situação da saúde na comunidade devido à atividade turística.), LAZER (Opinião do entrevistado quanto à situação dos espaços de lazer na comunidade devido à atividade turística) e Q_VIDA (Opinião do entrevistado quanto à situação da qualidade de vida na comunidade devido à atividade turística). Notou-se que a percepção dos entrevistados sobre os benefícios sociais que a atividade turística pode trazer para a comunidade estão diretamente ligados à geração de emprego, à distribuição de renda, a educação, ao lazer, e inversamente ligados às condições da saúde e a qualidade de vida.

Com esta análise pode-se confirmar, mais uma vez, que quando fala-se em turismo pensase imediatamente nos benefícios econômicos, principalmente na geração de emprego e conseqüentemente renda e sua distribuição. É interessante observar que a população analisada, quando pensa em benefícios sociais advindos do turismo, também percebe que 0 crescimento da atividade turística pode acarretar melhoria em algumas necessidades básicas como educação e lazer, que deveriam ser supridas pelo setor público de modo geral, servindo como alicerces para o desenvolvimento de um turismo sustentável.

Assim, através desta pesquisa, onde foram investigados os impactos positivos e negativos da atividade turística em uma comunidade receptora, no caso os moradores da Vila de Ponta Negra em Natal, capital do estado do Rio Grande do Norte, pode-se perceber o 
quanto são necessários estudos que enfoquem não só os aspectos econômicos e positivos desta atividade, que de um modo geral, são mais fáceis de ser analisados e quantificados, mas também aspectos que vislumbrem a sociedade como um todo, como social, ambiental, político, cultural, de modo que os elementos de uma dimensão se liguem com os de outra, em vez de optar por um ponto de vista exclusivo.

É nessa perspectiva de novos horizontes que nasce a premissa do desenvolvimento sustentável através do levantamento do uso de indicadores, cuja função é a de auxiliar a compreensão dos fatos sociais, onde se enfoca a participação social orientada por três eixos: a preservação ambiental, a eqüidade social e o crescimento econômico. Como expõe Dias (2003), sem a integração da comunidade local em todas as fases do processo não há desenvolvimento. Logo, para o turismo ser um meio positivo para o aumento da vida econômica, social, cultural e ambiental, é preciso que se volte para a população local, a fim de detectar os possíveis problemas e escolher o melhor método de avaliação condizente com a realidade encontrada. Portanto, a presente pesquisa oferece uma base sobre o estudo dos impactos sócio-ambientais que utiliza o conhecimento de indicadores e de métodos de avaliação sócio-ambiental, no intuito de pensar que sempre existirá degradação, mas que se pode minimizá-las. Deixar de estudar esses assuntos é que seria um desrespeito com a sociedade que clama por ajuda.

\section{REFERÊNCIAS BIBLIOGRÁFICAS}

ARCHER, Brian; COOPER, Chris. Os impactos positivos e negativos do turismo. In: THEOBALD, William F. (org.). Turismo global. 2. ed. São Paulo: SENAC São Paulo, 2002. (tradução Anna Maria Capovilla, Maria Cristina Guimarães Cupertino, João Ricardo Barros Penteado).

BISSOLI, M. A. A problemática econômica e social do espaço turístico. Revista COMUNICARTE. Campinas, n. 16-17, p. 116-149, 1992.

BRASIL. MINISTÉRIO DO TURISMO. INSTITUTO BRASILEIRO DE TURISMO EMBRATUR. Diretoria de Estudos e Pesquisas. Anuário Estatístico EMBRATUR 2006. v. 33. 236p. Dados de 2005.

DIAS, Reinaldo. Sociologia do turismo. São Paulo: Atlas, 2003.

FARIA, Wilma. Retirado da falada da Governadora. Disponível em: http://www.setur.rn.gov.br/index1.html. Acesso em: 17 de maio 2007.

FERRETI, E. R. Turismo e meio ambiente: uma abordagem integrada. São Paulo: Roca, 2002.

INSTITUTO BRASILEIRO DE GEOGRAFIA E ESTATÍSTICA - IBGE. Censo Demográfico 2000. Agregado por Setores Censitários dos Resultados do Universo. 2. ed. Rio de Janeiro: IBGE, 2003.

Pesquisa nacional por amostra de domicílios: síntese de indicadores 1996. Rio de Janeiro:IBGE, 1997 
OURIQUES, Helton Ricardo. A Produção do turismo: fetichismo e dependência. Campinas, SP: Alínea, 2005.

RUSCHMANN, Doris van de Meene. Turismo e planejamento sustentável: a proteção do meio ambiente. 7. ed. Campinas: Papirus, 2001.

SANTOS, M. et al (org). O novo mapa do mundo: fim de século e globalização. São Paulo: HUCITEC/ANPUR, 1994.

TRIOLA , Mario F. Introdução à Estatística. 9a ed. Rio de Janeiro. Editora LTC. 2005.

URRY, J. O olhar do turista: lazer e viagens nas sociedades contemporâneas. São Paulo: SESC/Studio Nobel, 1996. 